\title{
$\mathrm{M}|\mathrm{R}| \mathrm{S}$ Internet Journal Nitride Semiconductor Research
}

\section{Micro Epitaxial lateral overgrowth of GaN/sapphire by Metal Organic Vapour Phase Epitaxy}

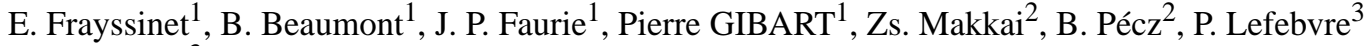 \\ and P. Valvin ${ }^{3}$ \\ ${ }^{1}$ Lumilog, 2720, Chemin de Saint Bernard, Les Moulins I, 06220 Vallauris, FRANCE, \\ ${ }^{2}$ Research Institute for Technical Physics and Matl. Sci., H-1525 Budapest, POBox 49, \\ ${ }^{3}$ Groupe d'Etude des Semiconducteurs, GES-CNRS,
}

(Received Tuesday, November 5, 2002; accepted Monday, December 9, 2002)

\begin{abstract}
GaN/sapphire layers have been grown by Metal Organic Vapour Phase Epitaxy (MOVPE). An amorphous silicon nitride layer is deposited using a $\mathrm{SiH}_{4} / \mathrm{NH}_{3}$ mixture prior to the growth of the low temperature $\mathrm{GaN}$ buffer layer. Such a process induces a 3D nucleation at the early beginning of the growth, resulting in a kind of maskless ELO process with random opening sizes. This produces a significant decrease of the threading dislocation (TD) density compared to the best GaN/sapphire templates. Ultra Low Dislocation density (ULD) GaN layers were obtained with TD density as low as $7 \times 10^{7} \mathrm{~cm}^{-2}$ as measured by atomic force microscopy (AFM), cathodoluminescence and transmission electron microscopy (TEM). Time-resolved photoluminescence experiments show that the lifetime of the A free exciton is principally limited by capture onto residual donors, similar to the situation for nearly dislocation-free homoepitaxial layers.
\end{abstract}

\section{Introduction}

The III-V compound semiconductor family has proven high performance in high-speed electronics, optical emitters, (i.e. laser diodes (LDs) and light emitting diodes (LEDs)) and detectors. However, for efficient operation, high crystalline quality is required. Growth technologies for large-scale substrates are currently very advanced for $\mathrm{Si}$ (and to a lesser extent, GaAs) and less advanced for InP and other III-V substrates. For GaN, bulk crystals are not readily available. Bulk GaN is intrinsically very difficult to grow because of the high vapour pressure of nitrogen at the melting point of GaN. GaN single crystals (about $1 \mathrm{~cm}^{2}$ ) are, however, produced by high temperature and high-pressure growth, mainly at UNIPRESS (Poland). [1]

Even though these crystals are very valuable for basic physics and demonstration of ultimate performance of devices, their size and potential production volume do not come close to meeting industrial needs.

Since there is no GaN bulk single crystal available, the entire technological development of $\mathrm{GaN}$ based devices relies on heteroepitaxy. GaN is currently grown epitaxially by MOVPE, Halide Vapour Phase Epitaxy (HVPE) and Molecular Beam Epitaxy (MBE). Most of the current device structures are grown on sapphire or $6 \mathrm{H}-\mathrm{SiC}$. Potentially more appropriate substrates like $\mathrm{LiAlO}_{2}, \mathrm{MgAl}_{2} \mathrm{O}_{4}, \mathrm{ScMgAlO}_{4}, 6 \mathrm{H}-\mathrm{SiC}, \mathrm{ZnO}$ and $\mathrm{Hf}$ have been tested in several laboratories. [2]

Even though good quality GaN epilayers have been obtained, none have been significantly better than GaN/ sapphire layers. The use of alternative substrates has therefore not yet solved the problem of obtaining a suitable substrate.

The lattice parameters and the thermal expansion coefficients of sapphire and $\mathrm{SiC}$ are not well matched to $\mathrm{GaN}$. The epitaxial growth of $\mathrm{GaN}$ on these substrates therefore generates huge densities of dislocations $\left(10^{9}\right.$ to $10^{11} \mathrm{~cm}^{-2}$ ). These dislocations propagate up to the surface to have an adverse effect on the performance of optical and electronic devices. Using appropriate nucleation layers reduces the dislocation density down to the mid $10^{8} \mathrm{~cm}^{-2}$ range. LDs were demonstrated in the late nineties with such defective layers. The real breakthrough in laser technology was the dramatic improvement of the laser diode lifetime at the end of 1997 [3] which reached up to 10000 hours. This was made possible with the implementation of epitaxial lateral overgrowth technology (ELO), which significantly reduces 
the dislocations density. [4] Even though ELO technology leads to outstanding increases in the lifetime of LDs, the ELO structure with its array of coalescence boundaries makes LD technology difficult. ELO technology also involves photolithographic steps that are time consuming and relatively expensive. It would be of great interest to keep the advantages of ELO without the requirement of making a mask on a GaN epitaxial layer by photolithography.

In previous papers [5] [6] [7] [8] [9] [10], we have shown that the treatment of the sapphire substrate by a mixture of silane + ammonia (hereafter called $\mathrm{Si} / \mathrm{N}$ treatment) induces a three dimensional growth mode at the first stage of the epitaxy of $\mathrm{GaN}$, thus reducing the dislocation density down to the mid $10^{8} \mathrm{~cm}^{-2}$ range. This process has been significantly improved and currently led to TD density below $10^{8} \mathrm{~cm}^{-2}$. In depth characterisations have shown that indeed the $\mathrm{Si} / \mathrm{N}$ treatment induces a non uniform SiN coverage, thus acting as micro mask.

\section{Experimental}

\subsection{D growth mode}

GaN growth by the two-dimensional growth mode has been made possible by the nitridation of the sapphire surface and by the two-step process. [11] Basically, the growth conditions have been optimized in order to obtain a continuous coverage of the substrate by the $\mathrm{GaN}$ nucleation layer (NL) and thereby producing flat GaN films at high temperature. This growth process however, leads to high defect densities $\left(\sim 10^{10}\right.$ dislocations $/ \mathrm{cm}^{2}$ ) and therefore better quality material is needed to achieve high performance and reliable devices.

By essentially using the epitaxial overgrowth principle, i.e. involving localized but maskless lateral overgrowth, a new growth process, referred to as the "3D growth process", has been implemented to obtain better quality GaN materials. Silicon has been reported to act as a "antisurfactant", i.e. it plays an important role in changing the growth mode from $2 \mathrm{D}$ to $3 \mathrm{D}$. [12] [13] [3] Using this antisurfactant effect of silicon, $\mathrm{GaN}$ quantum dots on $\mathrm{Al}_{\mathrm{X}} \mathrm{Ga}_{1-\mathrm{x}} \mathrm{N}$ surfaces have been realized by MOVPE. [12]

The exposure of the sapphire substrate prior to the deposition of a GaN NL under simultaneous silane and ammonia flows fundamentally influences the quality of $\mathrm{GaN}$ epilayers grown by MOVPE. This step of the growth process will be referred to as " $\mathrm{Si} / \mathrm{N}$ treatment". [6] [9] The NL is deposited between 500 and $600^{\circ} \mathrm{C}$. During the annealing up to $1080^{\circ} \mathrm{C}$ of this $\mathrm{NL}$, the Si/N process induces a dramatic morphological change of the GaN NL from a flat layer fully capping the substrate to a high density of 3D GaN islands (200-400 nm large and 100-200nm high) surrounded by the bare sapphire substrate (see Figure 1(a)).

It has been observed that two parameters are of critical importance to induce the 3D growth process:

1. the composition of the carrier gas $\left(\mathrm{N}_{2}\right.$ or $\left.\mathrm{N}_{2}+\mathrm{H}_{2}\right)$ and 2. the duration of the $\mathrm{Si} / \mathrm{N}$ treatment. [6] [9]

The $\mathrm{GaN}$ island formation is achievable only when $\mathrm{H}_{2}$ is present in the carrier gas. $\mathrm{H}_{2}$ seems to act as a "morphactant" as Eaglesham et al. [14] called impurities which favoured particular equilibrium shapes of islands. Recent studies [15] have also reported that the appearance of islands is strongly related to the $\mathrm{H}_{2}$ concentration in the growth chamber.

$\mathrm{GaN}$ epilayers grown following this process show $\mathrm{X}$ ray rocking curves with FWHM in the 180-360 arcsec range (for asymmetric reflections). Hall electron mobility in the $500-700 \mathrm{~cm}^{2} / \mathrm{V}$.s range at $300 \mathrm{~K}$, with background carrier concentration in the low $10^{16} \mathrm{~cm}^{-3}$, were obtained for $\mathrm{GaN}$ films grown with an adequate $\mathrm{Si} / \mathrm{N}$ treatment time. When measuring the PL intensity of 3D $\mathrm{GaN}$ layers, an increase in the intensity by a factor of about 20 is observed as compared to the $2 \mathrm{D}$-growth mode. This gain in radiative efficiency is well correlated to the decrease by a factor of about 50 in the dislocation density, thus confirming the non-radiative recombination nature of some of the dislocations in GaN. [16] [17] This Si/N treatment at the early stage of the growth was subsequently implemented by other groups and led to TD density in the low $10^{8} \mathrm{~cm}^{-2}$ range. [18] [19]

\subsection{Improvement of the $\mathrm{Si} / \mathrm{N}$ treatment}

The density of defects in material grown with a 3D mode was recently reduced down to the mid $10^{7} \mathrm{~cm}^{-2}$ range as measured by atomic force microscopy by an improved $\mathrm{Si} / \mathrm{N}$ treatment. Growth experiments were carried out in a $3 \times 2$ " low pressure MOVPE reactor using Trimethyl gallium (TMG) $(308 \mu \mathrm{mole} / \mathrm{min})$ as gallium source, and ammonia for providing $\mathrm{N}$, a V/III ratio of 1305 and $\mathrm{H}_{2}$ as carrier gas. After the $\mathrm{Si} / \mathrm{N}$ treatment, a $\mathrm{GaN}$ nucleation layer was deposited at $525^{\circ} \mathrm{C}$. The NL was then annealed at the growth temperature at $1000^{\circ} \mathrm{C}$, and afterwards growth proceeded. As described and analyzed in previous papers, [9] the whole growth process is monitored in real time by in situ laser reflectometry, Figure 2. In short, the nucleation layer deposited at low temperature on the $\mathrm{Si} / \mathrm{N}$ treated sapphire surface experienced a 2D-3D transition; this therefore increases the diffuse scattering of the laser beam and results in a continuous decrease of the reflectivity. Afterwards, the growth of $\mathrm{GaN}$ proceeds from the islands by lateral and vertical expansion to coalescence. These two stages correspond to the profound dip in the reflectivity and to the subsequent recovering of the reflectivity level, respec- 
tively. In the improved $\mathrm{Si} / \mathrm{N}$ treatment, the duration of the supply of $\mathrm{SiH}_{4}$ and $\mathrm{NH}_{3}$ lasts $360 \mathrm{sec}$. During the growth of this kind of samples, the full recovery of the reflectivity takes about 4 hours. The AFM scan of Figure 1 shows the size of islands for different $\mathrm{Si} / \mathrm{N}$ treatment durations. These islands are formed after deposition of amorphous $\mathrm{SiN}$ from $\mathrm{SiH}_{4} / \mathrm{NH}_{3}$ on the sapphire substrate, low temperature deposition of the $\mathrm{GaN}$ nucleation layer and then annealing at the growth temperature. As expected, the size of the 3D nuclei increases with the deposition time of $\mathrm{SiN}$. However, it cannot significantly increase beyond the actual value; otherwise the recovery time would be too long to obtain layers without pits. Nethertheless, such pitted layers exhibit a dislocation density in the low $10^{7} \mathrm{~cm}^{-}$ ${ }^{2}\left(<4 \times 10^{7} \mathrm{~cm}^{-2}\right)$

Delaying the coalescence has been recently achieved using a different approach, [19] [20]. Tuning the V/III ratio was used to control the coalescence of the island nucleation; TD densities of $1.5 \times 10^{8} \mathrm{~cm}^{-2}$ have been reported. [21]

The TD densities of the thick ULD GaN layers grown onto the nucleation layers shown in Figure 1(c) were determined by AFM scan and cathodoluminescence. Both methods give $7 \times 10^{7} \mathrm{~cm}^{-2}$.

\section{In depth characterisation}

\subsection{High resolution transmission electron micros- copy}

Transparent specimens for Transmission Electron Microscopy (TEM) were prepared by low angle ion milling [21] using $\mathrm{Ar}^{+}$bombardment at $10 \mathrm{kV}$. The energy of the impinging $\mathrm{Ar}^{+}$ions was decreased to 3 $\mathrm{keV}$ after perforation and even further down to $500 \mathrm{eV}$ in order to minimize ion beam damages. The specimens were investigated in a JEOL 3010 UMR microscope operating at $300 \mathrm{kV}$. High resolution images reveal that there is an amorphous region between GaN and sapphire, most likely SiN, (EDS shows some silicon). However, the amorphous material at the interface is a discontinuous layer. Indeed, the interface $\mathrm{SiN}$ layer is build of grains (20 nm height and 20-40 nm long). In figure 3 two small amorphous inclusions inside the GaN layer at the interface are seen. Actually the amorphous SiN layer acts as a micro mask, thereby leading to an ELO process at the micrometer scale.

The amorphous nature of the $\mathrm{SiN}$ discontinuous layer can be seen clearly. Indeed, the SiN layer acts as randomly distributed (in size and in location) openings, thereby inducing a lateral overgrowth process. The $\mathrm{GaN}$ layer over these "masks" is hexagonal and follows the usual epitaxial relationship to sapphire $\left(30^{\circ}\right.$ rotation around the 0001 axis). Sometimes the cubic sequence is also observed in grains of the NL between two $\mathrm{SiN}$ "inclusions" (Figure 3). However, these regions are also overgrown by hexagonal GaN. As further proof of the occurrence of an ELO mechanism, bending of threading dislocation occurs in this micro-ELO process as shown in Figure 4. More precisely, Figure 4 shows two TDs which propagate horizontally after bending.

Plan view samples of the top region of $\mathrm{GaN}$ were also prepared for TEM. Dislocation density was determined and value of $6 \times 10^{7} \mathrm{~cm}^{-2}$ was obtained. As AFM probes a larger area, the value of $7 \times 10^{7} \mathrm{~cm}^{-2}$ determined by AFM measurement is in good agreement with TEM data.

\subsection{Photoluminescence}

Figure 5 displays the near band gap low temperature PL spectra of GaN/sapphire grown following the present technology. The PL spectrum is dominated by the socalled $\mathrm{I}_{2}$ line, assigned to the donor-bound exciton, lying $\sim 6 \mathrm{meV}$ below the PL from the 1s-state of the free exciton with hole in the A valence band $\left(\mathrm{X}_{\mathrm{A}}\right)$. This assignment is confirmed by the reversal of intensity between these two lines above $\mathrm{T}=40 \mathrm{~K}$, due to thermal escape of excitons from the donor traps. The positions of the $\mathrm{X}_{\mathrm{A}}$ and $X_{B}$ lines prove that the layers are under biaxial compression [22] thus pushing the $X_{C}$ exciton towards much higher energies. The line at $3.512 \mathrm{eV}$ is then assigned to the $2 \mathrm{~s}$ state of the A exciton. The fluctuations of the strain are certainly at the origin of the present broadening of the lines. Nevertheless, apart from the broadening, this spectrum contains many of the features that are usually observed for high-quality homoepitaxial GaN layers [23], [24], including the two-electron satellite of the donor-bound exciton redshifted from the $I_{2}$ line by exactly the same amount $(21.6 \mathrm{meV})$ as for the homoepitaxial layers of Ref. [24]. These observations are further proof of the high quality of the layer.

\subsection{Time-resolved PL.}

The recombination dynamics of excess carriers in group III-nitrides is a key issue for the optimization of bluelight emitting diodes and laser diodes devices based on nitrides. Therefore, the relationships between growth parameters of $\mathrm{GaN}$ and optoelectronic properties are of critical importance. The recombination dynamics of $\mathrm{GaN}$ have been widely studied by several groups and reviewed in ref [25]. The main features are the following:

- The near-band edge emission spectrum appears dominated by excitonic recombination's. In most cases, the salient contribution arises from donor- 
bound excitons $\left(\mathrm{D}^{0} \mathrm{X}\right.$ or $\left.\mathrm{I} 2\right)$ while free excitons associated with the two upper valence bands $\left(\mathrm{X}_{\mathrm{A}}\right.$ and $X_{B}$ ) have been also identified in high quality material.

- In most cases, fast decay times have been reported. At $10 \mathrm{~K}$, they range from $14 \mathrm{ps}$ to $35 \mathrm{ps}$ for MOVPE GaN/sapphire [25] [26] [27] [28] [29] [30] [31] [32] Significantly different values, ranging from $6 \mathrm{ps}$ [33] to $\sim 170-200 \mathrm{ps}$ [34] and even to $\sim 300-500 \mathrm{ps}$ have been measured for thick HVPE layers. [35]

- For ELO, due to high quality of such materials, values ranging from 400 to $700 \mathrm{ps}$ were reported [36] [37] [38] [39]

All fast decay times have been unanimously assigned to parasitic non-radiative processes. Similar results have been reported for the I2 line. Decay times of $\sim 50-260 \mathrm{ps}$ [26] [27] [28] [29] [30] [31] [32] [33] [34] have been reported for MOCVD and decay times of up to $\sim 600$ ps have been reported for the best MBE-grown layers. While convincing attempts have been made to correlate fast decays to various parameters such as the intensity of the low-energy "yellow luminescence" [30] [40] or the presence of defects near the substrate-layer interface [35], up to now, no significant attempt to reach a limit close to the high value reported in MBE has been done using standard MOVPE.

Figure 6 shows the PL decays recorded on an ULD layer, at $\mathrm{T}=13 \mathrm{~K}$, on a time-scale of $\sim 5 \mathrm{~ns}$. The $\mathrm{I} 2$ line exhibits a nonexponential decay with initial decay time of $\sim 0.17 \mathrm{~ns}$, followed by a much slower and exponential decay, with time constant of $1.06 \mathrm{~ns}$. This result is totally comparable to that obtained on homoepitaxial (dislocation-free) GaN layers. [25] From the interpretation in Ref. [25], the slow decay is the intrinsic lifetime of the donor-bound exciton, but at short delays the recombination rate is enhanced by interaction of bound excitons with free ones. Even more remarkably, the decay dynamics of the $\mathrm{X}_{\mathrm{A}}$ line starts with a rather fast exponential decay, with $\hat{o} \sim 0.08 \mathrm{~ns}$, again comparable to the homoepitaxy of Ref. [24] but clearly with a long-lived component. The latter could not have been be observed if the decay was merely controlled by exciton trapping at nonradiative defects, as it is usually the case for lower-quality epitaxial layers. Instead, we believe that this slow decay may correspond to reabsorption phenomena, or rather, to the exciton-polariton nature of the recombining entity. This type of property can only be observed for high-quality samples, for which the nonradiative lifetime is much larger than the radiative lifetime. The figure also shows the fast decays recorded for the $X_{B}$ line and for the $2 s$ state of $X_{A}$.

Experiments performed using a smaller time window (1 ns) have allowed us to confirm the assignment of the lines: after the excitation laser pulse, the first line reaching its maximum intensity is the $X_{B}$ line. Then, $28 \mathrm{ps}$ later, the $\mathrm{X}_{\mathrm{A}}$ line and the higher energy line simultaneously reach their maximum, thus confirming the assignment to the $2 \mathrm{~s}$ state of the $\mathrm{X}_{\mathrm{A}}$ exciton. Finally, due to an evident transfer mechanism commented on in previous works, [25] the I2 line reaches its maximum, with a delay of $42 \mathrm{ps}$ from the $\mathrm{X}_{\mathrm{A}}$ line. This delay rapidly drops near zero when the temperature is raised to $40 \mathrm{~K}$.

\section{Discussion}

Experiments reveal two basic features about the role of the SiN layer. First, as already evidenced in previous papers, the occurrence of $\mathrm{Si}$ at the sapphire/GaN interface produces an "antisurfactant" effect, thereby inducing a 3D nucleation. After 3D nucleation, growth proceeds laterally from $\{1 \overline{1} 01\}$ facets until full coalescence. In addition there is at some stage of the process a spontaneous formation of micrograins as shown in HRTEM pictures. This then creates a kind of mask with randomly distributed sizes of openings. Bending of TDs at $90^{\circ}$ is observed, this is a well known feature in ELO when the lateral overgrowth is initiated from triangular stripes or pyramids.

\section{Conclusion}

Improvement of the $\mathrm{Si} / \mathrm{N}$ process results in $\mathrm{GaN} / \mathrm{sap}$ phire templates with TD densities as low as $7 \times 10^{7} \mathrm{~cm}^{-2}$. The FWHM of the near band gap PL recombination peak is lower than $2 \mathrm{meV}$. Time-resolved photoluminescence experiments show that the lifetime of the A free exciton is principally limited by capture onto residual donors, similar to the situation for nearly dislocationfree homoepitaxial layers.

\section{ACKNOWLEDGMENTS}

This work is supported by EU under contract EURONIM G5RD-CT-2001-00470. The authors wish to thank Dr. M. Leroux for helpful advices.

\section{REFERENCES}

[1] I. Grzegory and S. Porowski, Thin Solid Films,367, 281(2000)

[2] L. Liu and J.H. Edgar, Mat. Sci. Eng. Rep. R37, 61 (2002)

[3] S Nakamura, M Senoh, S Nagahama, N Iwasa, T Yamada, T Matsushita, H Kiyoku, Y Sugimoto, T Kozaki, H Umemoto, M Sano, K Chocho, Appl. Phys. Lett. 72, 211213 (1998).

[4] B. Beaumont, Ph. Vennéguès, P. Gibart, Phys. Stat. Sol. B 227, 1-43 (2001).

[5] S. Haffouz, H. Lahrèche, P. Vennéguès, B. Beaumont, F. Omnès, P. Gibart, Appl. Phys. Lett. 73, 1278 (1998). 
[6] P. Vennegues, B. Beaumont, S. Haffouz, M. Vaille, P. Gibart, J. Cryst. Growth 187, 167 (1998).

[7] S. Haffouz, B. Beaumont, Pierre Gibart, MRS Internet J. Nitride Semicond. Res. 3, 8 (1998).

[8] H. Lahreche, P. Vennegues, B. Beaumont, P. Gibart, J. Cryst. Growth 205, 245 (1999).

[9] S. Haffouz, B. Beaumont, P. Vénnègues, P. Gibart, Phys. Stat. Sol. A 176, 677 (1999).

[10] S. Haffouz, B. Beaumont, P. Vennéguès, P. Gibart, unpublished.

[11] H, Amano, N. Sawaki, I. Akasaki, Y. Toyoda, Appl. Phys. Lett. 48, 353 (1986).

[12] S Tanaka, S Iwai, Y Aoyagi, Appl. Phys. Lett. 69, 40964098 (1996).

[13] XQ Shen, S Tanaka, S Iwai, Y Aoyagi, Appl. Phys. Lett. 72, 344-346 (1998).

[14] D. J. Eaglesham, F. C. Unterwald, D. C. Jacobson, Phys. Rev. Lett. 70, 966 (1993).

[15] J. Han, T. -B. Ng, R. M. Biefeld, M. H. Crawford, D. M. Follstaedt, Appl. Phys. Lett. 71, 3114 (1997).

[16] SJ Rosner, EC Carr, MJ Ludowise, G Girolami, HI Erikson, Appl. Phys. Lett. 70, 420-422 (1997).

[17] T Sugahara, H Sato, M Hao, Y Naoi, S Kurai, S Tottori, K Yamashita, K Nishino, LT Romano, S Sakai, Jpn. J. Appl. Phys. 37, L398 (1998).

[18] S. Haffouz, V. Kirilyuk, P. R. Hageman, L. Macht, J. L. Weyher, P. K. Larsen, Appl. Phys. Lett. 79, 2390-2392 (2001).

[19] S. Sakai, T. Wang, Y. Morishima and Y. Naoi, J. Crystal Growth, 221, 334-337 (2000)

[20] S. Figge, T. Böttcher, S . Einfeldt and D. Hommel, J. Cryst. Growth, 221, 262 (2000)

[21] A. Barna, Mater. Res. Soc. Symp. Proc. 254, 3-22 (1992).

[22] B Gil , F Hamdani, H Morkoc, Phys. Rev. B 54, 76787681 (1996).

[23] K. Kornitzer, T. Ebner, M. Grehl, K. Thonke, R Sauer, C. Kirchner, V. Schwegler, M. Kamp, M. Leszczynski, I. Grzegory, S. Porowski, Phys. Stat. Sol. B 216, 5 (1999).

[24] K. P. Korona, Phys. Rev. B 65, 235312 (2002).

[25] J.S. Im, A. Moritz, F. Steuber, V. Haerle, F. Scholz, A. Hangleiter, Appl. Phys. Lett. 70, 631-633 (1997).

[26] C. I. Harris, B. Monemar, H. Amano, I. Akasaki, Appl. Phys. Lett. 67, 840-842 (1995).

[27] G. D. Chen, M. Smith, J. Y. Lin, H. X. Jiang, M. Asif Khan, C. J. Sun, Appl. Phys. Lett. 67, 1653-1655 (1995).

[28] W. Shan, T. Schmidt, X. H. Yang, J. J. Song, B. Goldenberg , J. Appl. Phys. 79, 3691-3696 (1996).

[29] A Hangleiter, JS Im, T Forner, V Härle, F Scholz, Mater. Res. Soc. Symp. Proc. 395, 559 (1996).

[30] K Okada, Y Yamada, T Tagushi, F Sasaki, S Kobayashi, T Tani, S Nakamura, G Shinomiya, Jpn. J. Appl. Phys. 35, L787 (1996).

[31] Y Kawakami, ZG Peng, Y Narukawa, S Fujita, S Fujita, S Nakamura, Appl. Phys. Lett. 69, 1414-1416 (1996).

[32] BK Meyer, D Volm, C Wetzel, L Eckey, JC Holst, P Maxim, R Heitz, A Hoffmann, I Broser, EN Mokhov, PG Baranov, C Qiu, Mater. Res. Soc. Symp. Proc. 378, 521-6 (1995).
[33] L. Eckey, R. Heitz, A. Hoffmann, I. Broser, B. K. Meyer, K. Hiramitsu, T. Detchprohm, H. Amano, I. Akasaki, Inst. Phys. Conf. Ser. 142, 927 (1996).

[34] J. P. Bergman, B. Monemar, H. Amano, I. Akasaki, K. Hiramatsu, N. Sawaki, T. Detchprohm, Inst. Phys. Conf. Ser. 142, 931 (1996).

[35] G. E. Buneau, W. D. Herzog, M. S. Ünlü, B. B. Goldberg, R. J. Molnar, Appl. Phys. Lett. 75, 838 (1999).

[36] L. Allègre, unpublished

[37] J. Holst, A. Kaschner, J. Christen, K. Hiramatsu, T. Shibata, N. Sawaki, Appl. Phys. Lett. 75, 3647 (1999).

[38] S. Hess, F. Walraet, R. A. Taylor, J. F. Ryan, B. Beaumont, P. Gibart, Phys. Rev. B 58, R15973 (1998).

[39] Michael Wraback, H. Shen, C. J. Eiting, J. C. Carrano, R. D. Dupuis, MRS Internet J. Nitride Semicond. Res. 5S1, W11.55 (2000).

[40] J. J. Song, W. Shan, T. Schmidt, X. H. Yang, A. Fisher, S. W. Hwang, B. Taheri, B. Goldenberg, R. Horning, A. Salvador, W. Kim, Ö. Atkas, A. Botchkarev, H. Morkoç, Proc. SPIE 2693, 86-96 (1996).

\section{FIGURES}

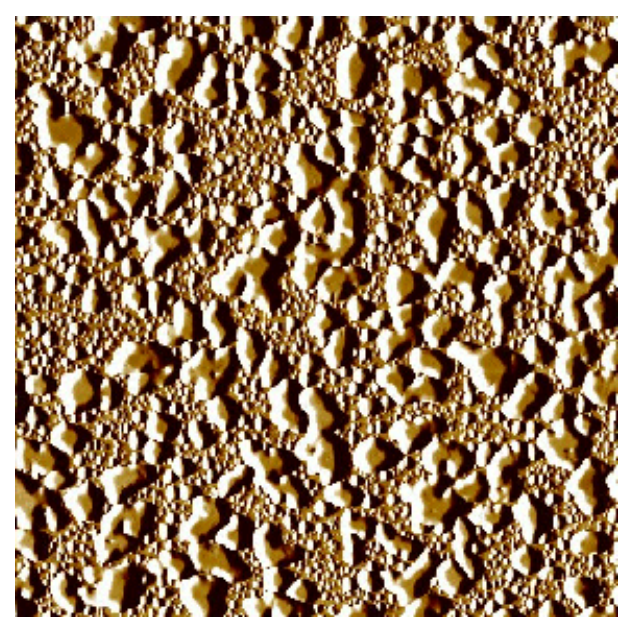

Figure 1a. AFM $\left(5 \times 5 \mu \mathrm{m}^{2}\right)$ scan showing the layer morphology for $180 \mathrm{sec} \mathrm{SiN}$ treatment time. The GaN islands density is about $1 \times 10^{9} \mathrm{~cm}^{-2}$. 


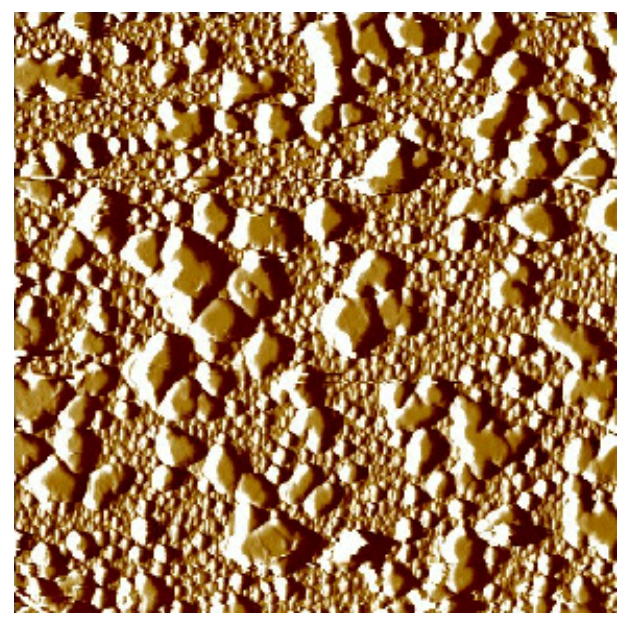

Figure 1b. AFM $\left(5 \times 5 \mu \mathrm{m}^{2}\right)$ scan showing the layer morphology for $300 \mathrm{sec} \mathrm{SiN}$ treatment time. The $\mathrm{GaN}$ islands density is about $5 \times 10^{8} \mathrm{~cm}^{-2}$.

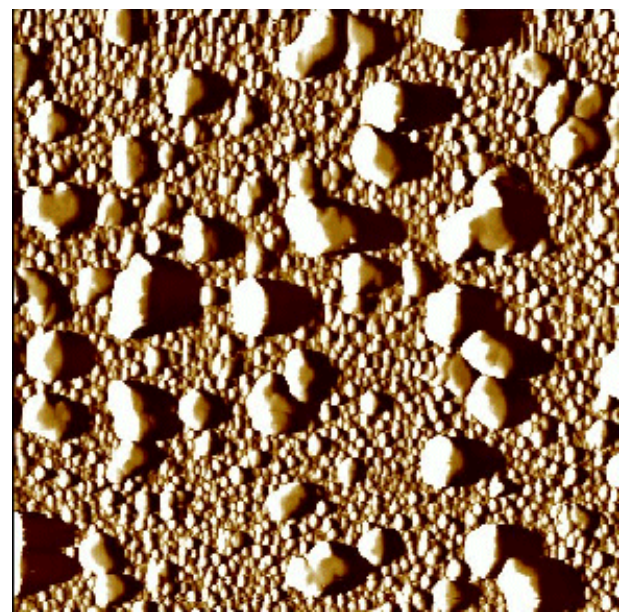

Figure 1c. AFM $\left(5 \times 5 \mu \mathrm{m}^{2}\right)$ scan showing the layer morphology for $480 \mathrm{sec} \mathrm{SiN}$ treatment time. The GaN islands density is about $3 \times 10^{8} \mathrm{~cm}^{-2}$.

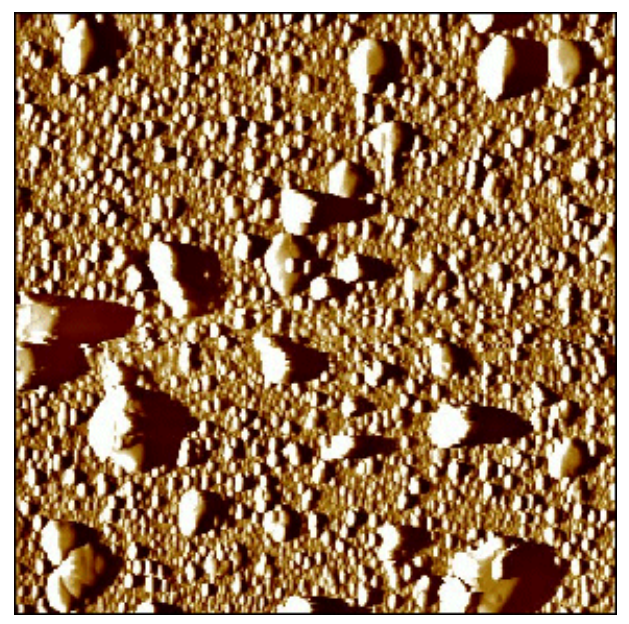

Figure 1d. AFM $\left(5 \times 5 \mu \mathrm{m}^{2}\right)$ scan showing the layer morphology for $720 \mathrm{sec} \mathrm{SiN}$ treatment time. The GaN islands density is about $1 \times 10^{8} \mathrm{~cm}^{-2}$.

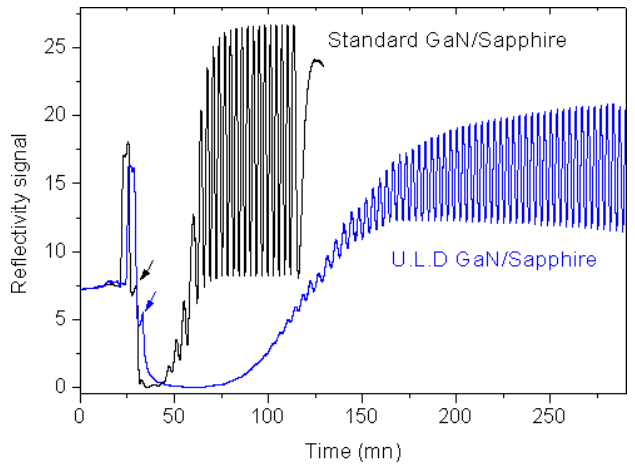

Figure 2. Comparison between reflectivity spectra recorded during the growth of GaN/sapphire standard epilayer and Ultra Low dislocation (ULD) GaN/sapphire. Arrows indicate where the growth starts.

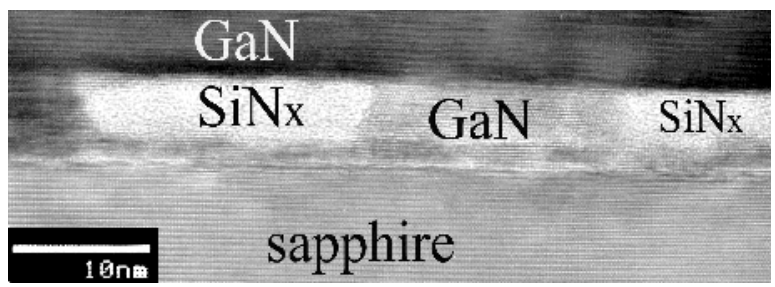

Figure 3. High Resolution image of the interface in a ULD GaN/sapphire sample. 


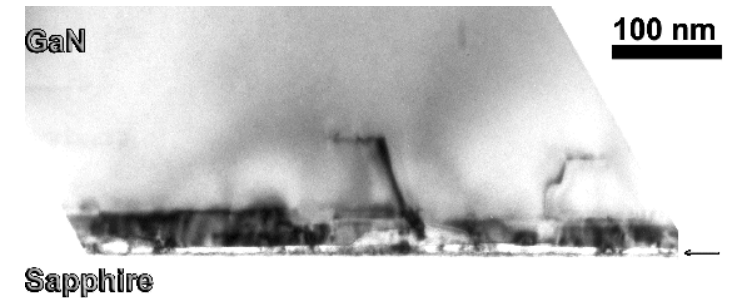

Figure 4. Cross-sectional bright field image of the ULD GaN/ sapphire sample showing the interface region. The arrow indicates the SiN coverage.

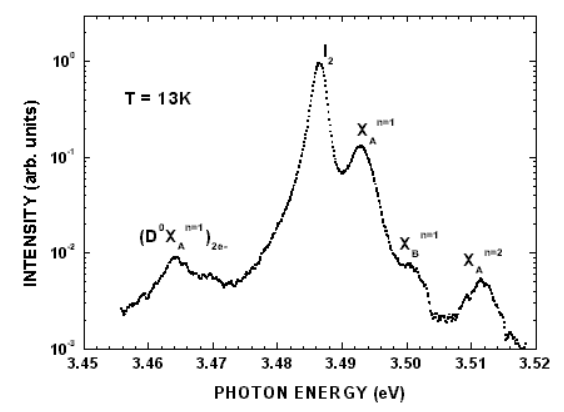

Figure 5. Near band gap low temperature photoluninescence of ULD GaN/sapphire

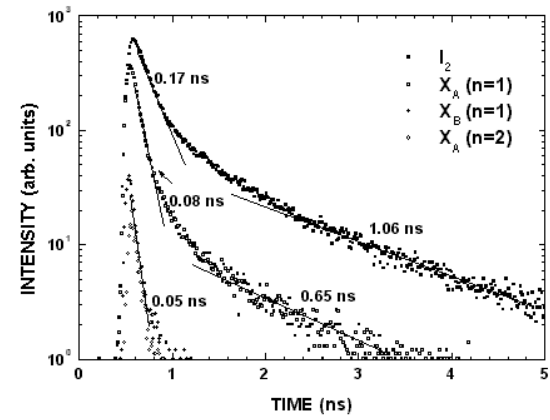

Figure 6. Decays of the free-excitons and I2 PL intensities recorded at $13 \mathrm{~K}$ 